Voix et Images

voixetimages

\title{
Bibliographie de Daniel Danis
}

\section{Camille Robidoux-Daigneault}

Volume 40, numéro 1 (118), automne 2014

Daniel Danis

URI : https://id.erudit.org/iderudit/1028027ar

DOI : https://doi.org/10.7202/1028027ar

Aller au sommaire du numéro

Éditeur(s)

Université du Québec à Montréal

ISSN

0318-9201 (imprimé)

1705-933X (numérique)

Découvrir la revue

Citer ce document

Robidoux-Daigneault, C. (2014). Bibliographie de Daniel Danis. Voix et Images, 40(1), 125-146. https://doi.org/10.7202/1028027ar d'utilisation que vous pouvez consulter en ligne.

https://apropos.erudit.org/fr/usagers/politique-dutilisation/ 


\section{B IB LIOG R A P IE DE DANIEL DAN IS ${ }^{1}$}

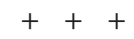

\section{CAMILLE ROBIDOUX-DAIGNEAULT}

Université de Montréal

\section{E U V RES}

\section{A. Th é ât re}

+ Celle-là, Montréal, Leméac, 1993, 91 p. (Rééditions: Paris, Théâtre Ouvert, coll. «Tapuscrit», 1993, 82 p. ; Arles, Actes Sud-Papiers, 2003, 59 p.)

+ Cendres de cailloux, Montréal, Leméac, 1994, 125 p. (Réédition: Arles, Actes Sud-Papiers, 2000, 128 p.)

+ Les nuages de terre, Paris, Théâtre Ouvert, coll. «Tapuscrit», 1994, 93 p.

+ Le chant du Dire-Dire, Paris, Thêâtre Ouvert, coll. «Tapuscrit», 1996, 88 p. (Rééditions: Paris, L'Arche, 2000, 80 p.; Montréal, Leméac, 2006, 75 p.)

+ La langue des chiens de roche, Paris, Théâtre Ouvert, coll. «Tapuscrit», 1998, 101 p. (Rééditions: Le langue-à-langue des chiens de roche, Paris, L'Arche, 2001, 92 p.; Montréal, Leméac, 2005, 77 p.)

+ Terre océane, photographies de Susan Coolen, Montréal, Dazibao, coll. «Des photographes», 2003, 112 p. (Réédition: Paris, L'Arche, 2007, 85 p.)

+ «Mille anonymes», Lexi-textes: Inédits et commentaires, t. VIII : Thêâtre national de la Colline, saison 2004-2005, Paris, L'Arche, 2004, p. 161-185.

+ e. Roman-dit, Montréal, Leméac, 2005, 125 p. (Version préliminaire parue sous le titre «Le roman-dit: le corps de mon mond", Lexi-textes: Inédits et commentaires, t. III : Théâtre national de la Colline, saison 1999-2000, Paris, L'Arche, 1999, p. 14-29.) (Réédition: Paris, L'Arche, coll. «Scène ouverte», 2005, 118 p.)

+ La trilogie des flous [« Je Ne», «Sommeil et rouge» et «Reneiges»], suivi de Mille anonymes et Ayiti tè frajil ou L'île saline, Paris, L'Arche, coll. «Scène ouverte», 2010, 181 p.

+ Dernier demain, Paris, L'Arche, à paraître.

+ Yukie, Paris, L'Arche, à paraître.

\section{B. Théâtre destiné à la jeunesse}

+ Le pont de pierres et la peau d'images, Paris, L'École des loisirs, 1996, 94 p.

+ Kiwi, Paris, L'Arche, 2007, 41 p.

1 L'auteure reconnaît les contributions successives de Maxime Loubert-Olijnik, Pauline Bouchet, Benoît C. Gauthier et Geneviève Brousseau Rivet. 
+ Sous un ciel de chamaille, Paris, L'Arche, coll. «Thêâtre jeunesse», 2007, 58 p.

+ Bled. D'après Le Petit Poucet de Charles Perrault, Paris, L'Arche, coll. «Théâtre jeunesse», 2008, $45 \mathrm{p}$.

+ "L'enfant lunaire», La fidélité [ouvrage collectif], Paris, L'Avant-scène thêâtre/La ComédieFrançaise, coll. «Les petites formes de la Comédie-Française», 2010, p. 11-29.

+ La scaphandrière, suivi de L'enfant lunaire, Paris, L'Arche, 2012, 89 p.

+ Rosépine, inédit, 2013.

\section{Textes de création dans des périodiques}

+ «La dernière réplique de l'auteur», collectif, Jeu. Revue de théâtre, nº 80, 1996, p. 217.

+ «Les actes d'avant l'écriture», Mœbius, n 91, 2001, p. 41.

+ «Dédiamanté», Møebius, n 138, 2013, p. 13-16.

\section{Article de périodique}

+ "L'acte de corporéliser un rêve», Écritures de thêâtre, nº 0, juillet-août-septembre 2000, p. 16-17.

\section{E. Livres $d^{\prime}$ art}

+ Humeurs, estampes d'artistes divers, accompagnées d'un texte de création de Daniel Danis, Alma, Biennale du dessin, de l'estampe et du papier-matière, 1996, [s. p.].

+ 9 vues, gravures sur bois de Louise Masson, poésies de Daniel Danis, présentation de RoseMarie Arbour, Montréal, Éditions du Passage, 2005, 53 p.

\section{F. Expositions}

+ Sculpture pour l'exposition Le cœur d'Ève et la grenade d'Adam, au CNE (Centre national d'exposition du mont Jacob), Ville de Saguenay, 1991.

+ Le retour de madame Tremblay avec feu son mari, exposition collective à la galerie L'œuvre de l'Autre, Chicoutimi, 1992.

+ Ève et Prométhée, exposition solo à l'Espace Virtuel, Chicoutimi, 1993.

\section{G. Enregistrements vidéo}

+ Le souffle de l'imparadis, mise en scène de Daniel Meilleur et Wêrê-Wêrê Liking, Montréal, Thêâtre d'Aujourd'hui [Fonds Thêâtre d'Aujourd'hui], 1994, DVD, 1 h 47 min 18 s.

+ Image de la vie et de la mort, conférence de Daniel Danis prononcée à l'Université du Québec à Montréal (UQAM), Montréal, 2007, DVD, 1 h 32 min 46 s.

\section{H. R a diofictions}

+ La beauté de l'innocence au royaume des ogres, texte de Jean-Luc Outers, Noëlle Renaude, Olivier Chiacchiari et Daniel Danis, RTBF/France Culture/Radio suisse romande/Radio-Canada [enregistrement devant public à la chapelle du Bon-Pasteur], 1998, 60 min.

+ Naufragium, réalisée par Line Meloche, coproduction Radio-Canada et Productions Pascale Graham, Montréal [enregistrement devant public à la salle Odyssée de la Maison de la culture de Gatineau], 1999, 55 min. 


\section{Matériel pédagogique}

+ «e: dossier pédagogique», Paris, Théâtre national de la Colline, 2005, 60 p., en ligne: http:// www.colline.fr/sites/default/files/archive/0.463551001281603607.pdf [page consultée le $1^{\text {er }}$ octobre 2014].

+ «Dossier pédagogique: Bled», Sartrouville, Théâtre de Sartrouville et des Yvelines, 2009, 22 p., en ligne: http://www.theatre-sartrouville.com/uploads/pdf/dossierpedagogique-bled.pdf [page consultée le $1^{\mathrm{er}}$ octobre 2014].

+ «Dossier pédagogique: Le pont de pierres et la peau d'images», France, Tournée «Théâtre à l'école», [s. d.], 17 p., en ligne: http://www.stevegibbs.net/cil1/dossier-pedagogique [page consultée le ${ }^{\text {er }}$ octobre 2014].

+ «Dossier pédagogique: La scaphandrière», Briançon, Théâtre du Briançonnais, [s. d.], 8 p., en ligne: http://www.theatre-du-brianconnais.eu/pdf/dossier_pedagogique_la_scaphandriere.pdf [page consultée le 20 mars 2014].

\section{TRADUCTIONS DES EUVRES DE DANIEL DANIS}

A) Ayiti tè frajil ou L'île saline

+ Lights After Life, traduction anglaise de Crystal Béliveau, inédit, 2006. [Version du chantier dirigé par Daniel Danis à l'Usine C, Montréal, mai 2006, qui deviendra par la suite An Ocean of Rain.]

+ An Ocean of Rain, livret pour opéra contemporain, traduction anglaise de Linda Gaboriau lors de la création de la pièce, inédit, 2008.

\section{B ) Celle-là}

+ That Woman, traduction anglaise de Linda Gaboriau, Vancouver, Talonbooks, 1998, 96 p.

+ Celle-là, traduction allemande d'Almut Lindner, Francfort-sur-le-Main, S. Fischer Verlag, 2001, $78 \mathrm{p}$.

+ Femeia aceea, traduction roumaine de Flavia Goian, Timisoara, Éditions Brumar, 2009, 67 p.

\section{C) Cendres de cailloux}

+ Stone and Ashes, traduction anglaise de Linda Gaboriau, Toronto, Coach House Press, 1995, $128 \mathrm{p}$.

+ Stone and Ashes, traduction anglaise de Tom McGrath, Édimbourg, inédit, 1995.

+ Lludw'r garreg', traduction galloise de Gareth Miles, Cardiff, inédit, 1997.

+ Cenere di sassi, traduction italienne de Gioia Costa, Milan, Edipus, 1999, 239 p.

+ Kieselasche/Staeinasche, traduction allemande de Andreas Jandl, Francfort-sur-le-Main, S. Fischer Verlag, 2000, 123 p.

+ «Kamien i popioly», traduction polonaise de Ewa Kuczkowska, Dialog : miesięcznik Zwiq̨zku Literatów Polskich, nº 48, 2003, p. 39-103.

+ Cenizas de piedras, traduction espagnole de Humberto Perez-Mortera, inédit, 2007.

+ Cenuşa de piatră, traduction roumaine de Monica Mihaescu, inédit, 2007.

+ Oske av stein, traduction norvégienne de Margunn Vikingstad, Oslo, Samlaget, 2011, p. 7-166.

+ Akmenų pelenai, traduction lituanienne de Dainius Gintalas, inédit, 2011. 


\section{D) Le chant du Dire-Dire}

+ The Song of the Say-Sayer, traduction anglaise de Linda Gaboriau, Vancouver, Talonbooks, 1998, $96 \mathrm{p}$.

+ Il Canto del Dire-Dire, traduction italienne de Gioia Costa, Milan, Edipus, 1999, 239 p.

+ Das Lied vom Sag-Sager, traduction allemande d'Uta Ackermann, Berlin/Francfort-sur-le-Main, Theater Heute/S. Fischer Verlag, 2000, 87 p.

+ O Canto do Dime-Dime, traduction espagnole et galicienne de Franck Meyer, inédit, 2002.

+ Dūda-dūdo daina, traduction lituanienne de Rasa Vasinauskaite, inédit, 2002.

+ Sananlaskijan laulu, traduction finnoise de Reita Lunatvuori, inédit, 2003.

+ Seie-Seiarens Song, traduction norvégienne d'Oj Skjelbred, inédit, 2003.

+ El Canto del Dime-Dime, traduction espagnole d'Elena Guiochins et de Boris Schoemann [dans le cadre d'une résidence de traduction du CEAD en 2001], Los Textos de la Capilla, nº 2, 2008, 78 p.

+ Pevanje Sokoćala, traduction serbe de Ljiljana Matic, Beograd, Altera, 2010, 157 p.

+ Songen om Seie-Seiaren, traduction norvégienne de Margunn Vikingstad, Oslo, Samlaget, 2011, p. 167-278.

+ Sangen om Sige-Sigeren, traduction néerlandaise de Michael Buchwald, inédit.

+ Traduction roumaine de Flavia Goian pour les Éditions Brumar en cours de réalisation.

+ Traduction suédoise de Johanna Enckell en cours de réalisation.

\section{E) e. Roman-dit}

+ Traduction allemande pour S. Fischer Verlag en cours de réalisation.

+ Traduction catalane en cours de réalisation.

\section{F) $\mathrm{Je} \mathrm{Ne}$}

+ Traduction anglaise de Linda Gaboriau, inédit.

\section{G) $K i w i$}

+ Kiwi, traduction allemande de Gerda Gensberger, Francfort-sur-le-Main, S. Fischer Verlag, 2008, $46 \mathrm{p}$.

+ Kiwi, traduction espagnole de Boris Schoemann [pour la production de Los endebles au Foro Contigo América, Mexico], inédit, 2011.

+ Traduction italienne de Christina Visentin en cours de réalisation.

\section{H) Le langue-à-langue des chiens de roche}

+ In the Eyes of Stone Dogs, traduction anglaise de Linda Gaboriau, Vancouver, Talonbooks, 1999, $96 \mathrm{p}$.

+ Tongue to Tongue, the Dogs of the Rocks, traduction anglaise pour l'Écosse d'Ella Wildridge [dans le cadre d'une résidence de traduction du CEAD], inédit, 2002.

+ Zungenspiel der Felsen Hunde, traduction allemande d'Almut Lindner, Francfort-sur-le-Main, S. Fischer Verlag, 2002, 112 p.

+ Akmeninių šunų bučiniai, traduction lituanienne de Dainius Gintalas, inédit, 2010.

+ Parenje planinskih pasa, traduction serbe de Ljiljana Matic, Beograd, Altera, 2010, 157 p.

+ I auga til steinhundar, traduction norvégienne de Margunn Vikingstad, Oslo, Samlaget, 2011, p. 279-349.

+ Поцелуи скальных псов, traduction russe de Rimma Genkina, inédit. 
+ Traduction italienne de Gioia Costa pour les éditions Edipus en cours de réalisation.

\section{I) Le pont de pierres et la peau d'images}

+ Die Steinbrücke und die Bilderhaut, traduction allemande d'Almut Lindner, Francfort-sur-leMain, S. Fisher Verlag, 1996, 65 p.

+ Il ponte di pietre e la pelle d'immagini, traduction italienne de Gioia Costa, Milan, Edipus, 1999, $239 \mathrm{p}$.

+ Het Toneelhuis, Traduction-adaptation flamande de Peter Seynaeve et Griet Op de Beeck, Anvers, inédit, 2003.

+ El Puente de piedras y la piel de imágenes, traduction espagnole d'Elena Guiochins et Boris Schoemann, Mexico, Anónimo Drama Ediciones, 2004, 59 p.

+ Traduction flamande de Luk Parceval, inédit.

\section{PRODUCTIONSTHÉ ÂTR A LES ${ }^{2}$}

A. A u Québec

1) Celle-là

+ Mise en scène de Louise Laprade, Montréal, ESPACE GO, 12 janvier au 13 février 1993.

+ Mise en scène de Benoît Lagrandeur, Jonquière, Théâtre La Rubrique, 31 janvier au 18 février 2001.

+ That Woman, mise en scène d'Emma Tibaldo, Montréal, Talisman Theatre, septembre 2006.

+ That Woman, mise en scène d'Emma Tibaldo, Montréal, Talisman Theatre et Infinitheatre, septembre 2007.

\section{2) Cendres de cailloux}

+ Mise en scène de Dominick Bédard, Jonquière, Théâtre La Rubrique, octobre 1993.

+ Mise en scène de Louise Laprade, Montréal, ESPACE GO, 16 novembre au 18 décembre 1993.

+ Mise en scène de Gilles Provost, Hull, Théâtre de l'̂̂le, 15 février au 18 mars 1994.

+ Mise en scène de Gill Champagne, Québec, Théâtre Blanc, 24 novembre au 3 décembre 1994.

+ Mise en scène de Luc Saint-Denis, Montréal, La Société des Anges, Espace Geordie, 3 au 14 février 2009.

\section{3) Le chant du Dire-Dire}

+ Mise en scène de René Richard Cyr, Montréal, ESPACE GO, 28 avril au 30 mai 1998.

+ Mise en scène d'Anne-Marie Riel, Gatineau, Espace René-Provost, 9 octobre au 8 novembre 2008.

+ Mise en scène de Marc Béland, Montréal, le Mimésis, église de l'Immaculée-Conception, 26 septembre au 20 octobre 2012.

\section{4) Le langue-à-langue des chiens de roche}

+ Mise en scène de René Richard Cyr, Montréal, Théâtre d'Aujourd'hui, en coproduction avec le Centre national des Arts (Ottawa), 10 janvier au 3 février 2001.

+ Mise en scène de Gill Champagne, Québec, Thêâtre du Trident, novembre 2004.

2 Il n'a pas toujours été possible de retracer les dates précises de certaines productions. 


\section{$5)$ Autres productions}

+ Le pont de pierres et la peau d'images, mise en scène de Jacinthe Potvin, Rimouski, Thêâtre du Bic, dans le cadre du Rendez-vous international du théâtre jeunes publics, 1996.

+ Sommeil et rouge, performance poétique [adaptation du poème chinois «Chant de l'éternel regret» de Po Kiu-yi], mise en œuvre de Daniel Danis, Montréal, Usine C, 2006.

+ Terre océane, mise en scène de Gill Champagne, coproduction Théâtre de Quat'Sous, Thêâtre du Trident, Logomotive Théâtre et Compagnie Daniel Danis, arts/sciences, Montréal, Théâtre d'Aujourd'hui, 23 octobre au 17 novembre 2007.

+ Yukie, écriture scénique de Daniel Danis, Québec, coproduction Compagnie Daniel Danis, arts/ sciences, Carrefour international de théâtre de Québec et autres, Caserne Dalhousie, 3 au 6 juin 2010.

+ Les sens [de Michel Marc Bouchard, Sylvie Bouchard, Daniel Danis, Jean-Rock Gaudreault, Larry Tremblay et Pierre-Michel Tremblay], mise en scène de Benoît Lagrandeur, Jonquière, Thêâtre La Rubrique, 26 janvier au 12 février 2011.

+ Mille anonymes, écriture scénique de Daniel Danis, coproduction Compagnie Daniel Danis, arts/sciences, Productions Recto-Verso, Festival TransAmériques et Carrefour international de théâtre de Québec, Québec/Montréal, Salle Multi de Méduse/ESPACE GO, 24 au 28 mai 2011/30 mai au 2 juin 2011.

+ L'enfant lunaire, mise en scène de Daniel Danis, Québec, Productions Recto-Verso, en collaboration avec Hexagone Scène Nationale Arts Sciences, 2013.

+ Rosépine, mise en scène de Jeannot Boudreault, Saguenay, Thêâtre Les Amis de Chiffon, salle Murdock, 3 au 22 décembre 2013.

\section{B. Au Canada hors Québec}

1) Cendres de cailloux

+ Stone and Ashes, mise en scène de Jackie Maxwell, Toronto, The Factory Theatre, 1994.

+ Stone and Ashes, mise en scène de Sandhano Schultze, Vancouver, Pi Theatre, 4 au 21 janvier 1996.

+ Stone and Ashes, mise en scène de Jarvis Hall, Calgary, Theatre in Exile, 1998.

\section{2) Autres productions}

+ That Woman, mise en scène de John Cooper, Edmonton, Theatre Network, 1998.

+ Thunderstruck, or The Song of the Say-Sayer, mise en scène de Stephanie Kirkland, Vancouver, Pi Theatre, 10 au 25 mars 2000.

+ Le pont de pierres et la peau d'images, mise en scène d'Anne-Marie Riel, Ottawa, Thêâtre Jeunesse en tête, 2006.

+ Sous un ciel de chamaille, mise en scène de Daniel Danis et Anne-Marie Riel, Ottawa, Thêâtre Jeunesse en tête, avril 2007.

+ Kiwi, mise en scène d'Anne-Marie Riel, Ottawa, Théâtre Jeunesse en tête, 2009.

+ In the Eyes of Stone Dogs, mise en scène de Christopher Bedford, Toronto, Evolution Theatre, 19 au 26 novembre 2011.

\section{En Europe}

1) Celle-là

+ Mise en scène d'Alain Françon, Paris, Théâtre Ouvert, 17 janvier au 16 février 1995. 
+ That Woman, mise en scène de Cathie Boyd, Édimbourg, Cryptic Theatre, 1997.

+ Mise en scène de Jean-Pierre Ryngaert, Association jurassienne d'animation culturelle, tournée dans le Jura suisse, 2003.

\section{2) Cendres de cailloux}

+ Stone and Ashes, mise en scène de Ian Brown, Édimbourg, Traverse Theater, 1994.

+ Mise en scène d'Olivier Maurin, Lyon, Compagnie Lhoré Dana, 1995.

+ Mise en scène de Lukas Hemleb, Charleroi, Théâtre de l'Ancre, 1995.

+ Mise en scène de Rosemary Fournier, Rouen, Logomotive Théâtre, 1996.

+ Lludw'r garreg', mise en scène de Ian Rowlands, Cardiff, Theatr Y Byd, 1997.

+ Stone and Ashes, mise en scène de Jackie Doyle, Belfast, Prime Cut Productions, 1997.

+ Kieselasche, mise en scène d'Inka Neubert, Cologne, INTEATA im Haus ORANGE, octobre 2003.

+ Mise en scène de Vincent Goethals, Théâtre en scène, en tournée en France, 2004-2005.

+ Kamien i popioly, mise en scène d'Artur Urbanski, Varsovie, Scena DuĐa, septembre 2010.

\section{3) Le chant du Dire-Dire}

+ Mise en scène d'Alain Françon, Paris, Théâtre national de la Colline, 15 septembre au 23 octobre 1999.

+ Das Lied vom Sag-Sager, mise en scène de Peter Wittenberg, Berlin, Schaubühne am Lehniner Platz, 2000.

+ Sananlaskijan laulu, mise en scène d'Anca Bradu, Helsinki, Finnish National Theatre, octobre 2003.

\section{4) Le langue-à-langue des chiens de roche}

+ Mise en scène de Michel Didym, Paris, Théâtre du Vieux-Colombier, 2001.

+ Mise en scène de Christine Farenc, Paris, Théâtre du Voir, 7 mars au 3 avril 2006.

\section{5) Le pont de pierres et la peau d'images}

+ Mise en scène de Nabil El Azan, Paris, Espace Prévert, 1997.

+ Mise en scène de Rosemary Fournier, Rouen, Logomotive Théâtre, 1999.

+ Mise en scène de Vincent Goethals, Lille, Le Grand bleu, 1999.

+ Il Ponte di pietre i la pelle d'immagini, mise en scène de Lia Chiappara, Sicile, Teatro Libero, novembre 2000.

+ Mise en scène de Jacques Nichet, Toulouse, Théâtre de la Cité, 2000.

+ Mise en scène de Dominique Catton, Genève, Am Stram Gram, 2001.

\section{6) $K i w i$}

+ Écriture scénique de Daniel Danis, coproduction Le Grand Bleu, Compagnie Daniel Danis, arts/ sciences et Centre Dramatique, Maubeuge, Manège de Maubeuge, 6 au 8 décembre 2007. Aussi présentée au Festival d'Avignon du 7 au 27 juillet 2008. Tournée en France, au Québec et en Allemagne.

+ Mise en scène de Guylaine Rivard, coproduction La Tortue Noire, ManiganSes et La Luna è Azzurra, San Miniato, Festival La Luna è Azzurra, 2007. Tournée en France et au Québec. 


\section{7) Autres productions}

+ Les nuages de terre, mise en scène de Wêrê-Wêrê Liking et Daniel Meilleur, La Chartreuse de Villeneuve-lez-Avignon/Festival international des francophonies en Limousin, Limoges, 1994.

+ e. Roman-dit, mise en scène d'Alain Françon, Paris, Théâtre national de la Colline, 26 janvier au 27 février 2005. Aussi présentée dans le cadre du Festival de Théâtre des Amériques en juin 2005.

+ Bled, mise en scène de Daniel Danis, Sartrouville, Thêâtre de Sartrouville/CDN, janvier 2009.

+ Terre océane, mise en scène de Véronique Bellegarde, Grenoble, Maison de la culture de Grenoble, janvier 2010.

+ Sous un ciel de chamaille, mise en scène de Wilma Lévy, Marseille, Compagnie des Passages, 14 au 19 février 2011. Tournée en France.

+ La scaphandrière, mise en scène d'Olivier Letellier, Saint-Nazaire, Thêâtre du Phare, 2011. Tournée en France. Présentée à Montréal au Théâtre Outremont du 17 au 19 novembre 2012 et à Québec au Théâtre Les gros becs du 21 au 23 novembre 2012.

\section{A u Mexique}

+ El Canto del Dime-Dime [Le chant du Dire-Dire], mise en scène de Boris Schoemann, Mexico, Los Endebles, 2003.

+ El Puente de piedras y la piel de imágenes [Le pont de pierres et la peau d'images], mise en scène de Boris Schoemann, Mexico, Los Endebles, mai 2005.

+ Kiwi, mise en scène de Boris Schoemann, Mexico, Los Endebles, 12 au 13 novembre 2011.

\section{PRODUCTIONS RADIOPHONIQUES ${ }^{3}$}

+ e. Roman-dit, réalisée par Blandine Masson, France Culture, 2004, 1 h 51 min 37 s.

+ Celle-là, réalisée par Georges Peyrou, France Culture, 2008, 90 min 11 s.

+ Kiwi, réalisée par Jean-Matthieu Zahnd, France Culture, 2008, 29 min 18 s.

+ Terre océane, réalisée par Jean-Matthieu Zahnd, France Culture, 2008, 1 h 24 min 32 s.

+ Bled, réalisée par Marguerite Gateau, France Culture, 2009, 29 min 59 s.

+ Ayiti tè frajil, réalisée par Juliette Heymann, France Culture, 2010, 56 min 23 s.

+ Mille anonymes, réalisée par François Christophe, France Culture, 2011, 60 min 6 s.

\section{PRIX ET D IS T INCTIONS}

+ Prix Tchicaya U Tam'Si, Radio France International «Théâtre 92 (Texte et Dramaturgie du Monde)", pour Cendres de cailloux, 1992.

+ Premier Prix au Concours International de Manuscrits du Festival de Maubeuge (France) pour Cendres de cailloux, 1992.

+ Prix du Gouverneur général du Canada pour Celle-là, 1993.

+ Prix de la critique (Montréal) pour Celle-là, 1993.

+ Prix du meilleur texte original à la Soirée des masques pour Cendres de cailloux, 1994.

+ Prix de la meilleure création d'une pièce de langue française du Syndicat Professionnel de la Critique Dramatique et Musicale (Paris) pour Celle-là, 1995.

+ Prix de la meilleure création d'une pièce de langue française du Syndicat Professionnel de la Critique Dramatique et Musicale (Paris) pour Le chant du Dire-Dire, 2000.

3 Nous avons uniquement recensé les radiodiffusions de langue française, mais il est à noter que les pièces Celle-là et Le chant du Dire-Dire ont également été diffusées en Allemagne et au Danemark à plusieurs reprises. 
+ Nommé chevalier de l'ordre des Arts et des Lettres de la République française, 2000.

+ Prix du Gouverneur général du Canada pour Le langue-à-langue des chiens de roche, 2002.

+ Prix littéraire Abitibi-Consolidated du Salon du livre du Saguenay-Lac-St-Jean pour Terre océane, 2003.

+ Grand Prix de littérature dramatique (France) pour e. Roman-dit, 2006.

+ Prix du Gouverneur général du Canada pour Le chant du Dire-Dire, 2007.

+ Prix Louise-LaHaye remis par le Centre des auteurs dramatiques (CEAD) pour Kiwi, 2008.

+ Prix littéraire Abitibi-Bowater du Salon du livre du Saguenay-Lac-Saint-Jean pour Kiwi, 2008.

+ Prix allemand du thêâtre jeunesse (Deutscher Jugendtheaterpreis) pour Kiwi, 2008.

\section{VI.RÉCEPTION CR ITIQUE}

\section{A. Mémoires et $t$ hè ses}

+ LESAGE, Marie-Christine, Modalités analogiques et structures imagées du langage dramatique actuel. Étude du Syndrome de Cézanne de Normand Canac-Marquis et de Celle-là de Daniel Danis, thèse de doctorat, Québec, Université Laval, 1998, 368 f.

+ GENDRON, Adeline, Hybridation textuelle et prescription de lecture chez Normand Chaurette, Daniel Danis et René-Daniel Dubois, mémoire de maîtrise, Montréal, Université de Montréal, 2002, $151 \mathrm{f}$.

+ HEMMERLÉ, Marie-Aude, La parole-matière. Le statut de la parole dans trois pièces de Daniel Danis: Cendres de cailloux, Le chant du Dire-Dire, Le langue-à-langue des chiens de roche, mémoire de maîtrise, Paris, Université Sorbonne Nouvelle-Paris 3, 2002, 61 f.

+ TREMBLAY, Isabelle, La narrativité dans la dramaturgie québécoise des années quatre-vingt-dix: aperçu du phénomène à travers des textes de Daniel Danis, de René-Daniel Dubois et de Larry Tremblay, mémoire de maîtrise, Québec, Université Laval, 2002, 139 f.

+ BLONDE, David, De Gauvreau à Danis: repères pour une poétique de la langue théâtrale, mémoire de maîtrise, Ottawa, Université d'Ottawa, 2003, 172 f.

+ CHÉNETIER-ALEV, Marion, L'oralité dans le théâtre contemporain: Herbert Achternbusch, Pierre Guyotat, Valère Novarina, Jon Fosse, Daniel Danis, Sarah Kane, thèse de doctorat, Paris, Université Sorbonne Nouvelle-Paris 3, 2004, $643 \mathrm{f}$.

+ VALÉRO, Julie, Figuration des corps. Étude autour de trois œuvres: Le langue-à-langue des chiens de roche de Daniel Danis, Des couteaux dans les poules de David Harrower et 4.48 Psychosis de Sarah Kane, mémoire de maîtrise, Paris, Université Sorbonne Nouvelle-Paris 3, 2004, $127 \mathrm{f}$.

+ GOIAN, Flavia Natalia, La question identitaire comme enjeu d'une parole codée dans les écrits rêviques: La trilogie des souliers de Daniel Danis, mémoire de maîtrise, Paris, Université Sorbonne Nouvelle-Paris 3, 2005, $75 \mathrm{f}$.

+ GAGNON-CARIGNAN, Virginie, Dynamique communicationnelle et aliénation identitaire. Étude de la pièce Celle-là, mémoire de maîtrise, Québec, Université Laval, 2006, 130 f.

+ BACQUET, Hélène, Le chant des muets: mémoire, parole et mélodie dans Le Petit Köchel de Normand Chaurette, Le chant du Dire-Dire de Daniel Danis et Les mains bleues de Larry Tremblay; suivi du texte dramatique Chanson de toile, mémoire de maîtrise, Montréal, Université du Québec à Montréal, 2007, 97 f.

+ LAVOIE, Catherine, Tourner en rond: reconnaissance, jeu de langage et victimisation dans Cendres de cailloux de Daniel Danis, mémoire de maîtrise, Chicoutimi, Université du Québec à Chicoutimi, 2007, $116 \mathrm{f}$. 
+ CANELAS, Marion, Écritures dramatiques et écritures romanesques contemporaines. Traces de genre échangées et définition des frontières dans Cendres de cailloux de Daniel Danis et Loin d'eux de Laurent Mauvignier, mémoire de maîtrise, Paris, Université Sorbonne Nouvelle-Paris 3, 2008, 44 f.

+ HEMMERLÉ, Marie-Aude, Représentations et figurations des dramaturgies québécoises contemporaines. De Normand Chaurette à Daniel Danis, thèse de doctorat, Paris, Université Sorbonne Nouvelle-Paris 3, 2010, $352 \mathrm{f}$.

+ PADOVANI, Delphine, Le théâtre du monde chez les auteurs dramatiques contemporains francophones. Valère Novarina, Pierre Guyotat, Didier-George Gabily, Olivier Py, Joël Pommerat, Daniel Danis, thèse de doctorat, Montpellier, Université Paul-Valéry, 2011, 591 f.

+ VÉRICEL, Ludivine, Des masques et des masques, après la catastrophe. Étude comparée des œuvres de Normand Chaurette et de Daniel Danis, mémoire de maîtrise, Montréal, Université du Québec à Montréal, 2012, $132 \mathrm{f}$.

+ NEPVEU-VILLENEUVE, Maude, «Émerger pour le temps des partages. » La scène comme lieu de restauration de l'unité communautaire dans Celle-là, Cendres de cailloux et Le chant du DireDire de Daniel Danis, mémoire de maîtrise, Montréal, Université du Québec à Montréal, 2013, $109 \mathrm{f}$.

+ GAUTHIER, Benoît, La relation texte/scène en phase de reconfiguration. Propositions théoriques autour de Terre océane de Daniel Danis, mémoire de maîtrise, Montréal, Université de Montréal, 2014, $121 \mathrm{f}$.

\section{B. Parties d'ouvrages}

+ BERNARD, Andrès et Pascal RIENDEAU, «La dramaturgie depuis 1980 », Réginald Hamel (dir.), Panorama de la littérature québécoise contemporaine, Montréal, Guérin, 1997, p. 208-239.

+ MOSS, Jane, «Daniel Danis et la dramaturgie de la parole», Betty Bednarski et Irène Oore (dir.), Nouveaux regards sur le théâtre québécois, Montréal/Halifax, XYZ éditeur/Dalhousie French Studies, coll. «Documents», 1997, p. 117-128.

+ DESMEULES, Georges et Christiane LAHAIE, Les personnages du thêâtre québécois, Québec, L'instant même, coll. «Connaître», 2000, p. 104.

+ LESAGE, Marie-Christine, «La dynamique de la mémoire: fragmentation et pensée analogique», Guy Poirier et Pierre-Louis Vaillancourt (dir.), Le bref et l'instantané. À la rencontre de la littérature québécoise du xxI siècle, Ottawa, Éditions David, 2000, p. 173-203.

+ GODIN, Jean-Cléo, «Le retour du texte et de l'auteur», Dominique Lafon (dir.), Le théâtre québécois, 1975-1995, Montréal, Fides, coll. «Archives des lettres canadiennes», 2001, p. 57-71.

+ MAGNAN, Lucie-Marie et Christian MORIN, 100 pièces du thêâtre québécois qu'il faut lire et voir, Québec, Nota bene, coll. «NB poche», 2002, p. 197-200; 295-298.

+ LAFON, Dominique, "La langue-à-dire du thêâtre québécois», Hélène Beauchamp et Gilbert David (dir.), Théâtres québécois et canadiens-français au XXe siècle. Trajectoires et territoires, Montréal, Presses de l'Université du Québec, 2003, p. 181-196.

+ PAPACHRISTOS, Katherine, «Le regard comme point de vue narratif dans le théâtre de Daniel Danis» [sur Celle-là et Cendres de cailloux], Chantal Hébert et Irène Perelli-Contos (dir.), La narrativité contemporaine au Québec, t. II: Le théâtre et ses nouvelles dynamiques narratives, Québec, Presses de l’Université Laval, 2004, p. 199-213.

+ HEMMERLÉ, Marie-Aude, «Daniel Danis, Celle-là», Jean-Pierre Ryngaert (dir.), Nouveaux territoires du dialogue, Arles/Paris, Actes Sud/Conservatoire national supérieur d'art dramatique, coll. «Actes Sud-Papiers/Apprendre», 2005, p. 132-136. 
+ BIRON, Michel, François DUMONT et Élisabeth NARDOUT-LAFARGE, Histoire de la littérature québécoise, Montréal, Boréal, coll. «Boréal compact», 2007, p. 589-590.

+ L'HÉRAULT, Pierre, «En bref» [Cendres de cailloux], L'assemblée pensante. Chroniques thêâtrales, 1994-2007, textes réunis, présentés et établis par Sylvain Lavoie, Ginette Michaud et Élisabeth Nardout-Lafarge, Québec, Nota bene, coll. «Nouveaux essais Spirale», 2009, p. 59-60.

+ MATIĆ, Ljiljana, «Daniel Danis, chantre québécois de la nature», Jelena Novaković, Slobodan Pajović et Vladimir Gvozden (dir.), (Re)connecting Through Diversity: Canadian Perspective/ Les relations dans la diversité: perspectives canadiennes, Belgrade, Association serbe d'études canadiennes, 2011, p. 205-215.

\section{C. É t u d e s}

+ DURIF, Eugène, «Le ratage premier de l'amour», Les Cahiers de Prospero, n 1, 1993, p. 36.

+ LESAGE, Marie-Christine, "Archipels de mémoire. L'œuvre de Daniel Danis», Jeu. Revue de thêâtre, nº 78, 1996, p. 79-89.

+ MOSS, Jane, "Cendres de cailloux et le langage lapidaire de Daniel Danis», Dalhousie French Studies, vol. 42, printemps 1998, p. 173-185.

+ DESROCHERS, Nadine, "Le récit dans le thêâtre de Daniel Danis», L'Annuaire théâtral, nº 26, automne 1999, p. 119-132.

+ MILES, Gareth, «Lludw'r Garreg: traduire Cendres de cailloux en gallois», L'Annuaire théâtral, $n^{\circ} 27$, printemps 2000, p. 100-107.

+ RYNGAERT, Jean-Pierre, «Le Québec comme réserve d'émotion et territoire de l'âme pour les Français. Michel Tremblay et Daniel Danis à Paris», L'Annuaire théâtral, n² 27, printemps 2000, p. 147-159.

+ TANNER, Michel, «Le théâtre québécois et la communauté française de Wallonie: rencontres et conflits», L'Annuaire thêâtral, n 27, 2000, p. 76-81.

+ BLONDE, David, «Entre Oreste et Barbe-Bleue: la violence dans la scène familiale québécoise, 1981-2002", L'Annuaire thêâtral, no 32, automne 2002, p. 129-149.

+ DAVID, Gilbert, «Comment se joue la résistance à la représentation? L'exemple du théâtre de Daniel Danis», Études théâtrales, ns 24-25, décembre 2002, p. 205-214.

+ CHÉNETIER, Marion, «Les voix-pas-là de Daniel Danis», Le nouveau recueil, nº 66, 2003, p. 100-105.

+ JUBINVILLE, Yves, «La vie en reste. Sur quelques exemples de témoignages dans la dramaturgie québécoise actuelle (Danis, Chaurette, Tremblay)», Chantal Hébert et Irène Perelli-Contos (dir.), La narrativité contemporaine au Québec, t. II: Le thêâtre et ses nouvelles dynamiques narratives, Québec, Presses de l'Université Laval, 2004, p. 47-60.

+ VIGEANT, Louise, «Guerre et paix: si loin, si proche», Jeu. Revue de thêâtre, nº 115, juin 2005, p. $44-48$.

+ HEMMERLÉ, Marie-Aude, "Le récit comme avatar du dialogue dans le thêâtre de Daniel Danis», Loxias, $\mathrm{n}^{\circ}$ 13, mai 2006, en ligne: http://revel.unice.fr/loxias/document.html?id=1113Loxias (page consultée le $1^{\text {er }}$ octobre 2014).

+ GUAY, Hervé, «Le nouveau désarroi amoureux et quelques vertiges identitaires», Jeu. Revue de théâtre, nº 120, 2006, p. 96-104.

+ HEMMERLÉ, Marie-Aude, "Les nouvelles écritures dramatiques du Québec», Registres. Revue d'études théâtrales, nºs 11-12, hiver 2006-printemps 2007, p. 216-225.

+ LIZOTTE, Audrey, «Daniel Danis et Michel Marc Bouchard. Regards croisés sur une même réalité», Québec français, nº 146, été 2007, p. 38-41. 
+ DAVID, Gilbert, «Le langue-à-langue de Daniel Danis. Une parole au corps à corps», Études françaises, vol. XLIII, nº 1, 2007, p. 63-81.

+ MOSS, Jane, «Daniel Danis, New Quebec Dramaturgy, and World Theatrical Literature in French", Contemporary French and Francophone Studies, vol. XIII, n 1, janvier 2009, p. 25-33.

+ HEMMERLÉ, Marie-Aude, «Figures du double dans e de Daniel Danis», L'Annuaire théâtral, $\mathrm{n}^{\circ} 45$, printemps 2009, p. 175-187.

+ BOUCHET, Pauline, «La dramaturgie des "flous". Polyphonie et réflexivité dans les créations récentes de Larry Tremblay et Daniel Danis», L'Annuaire théâtral, n 47, printemps 2010, p. 69-83.

+ DUFIET, Jean-Paul, «Dire au thêâtre. Le chant du Dire-Dire de Daniel Danis», Alessandra Ferraro et Élisabeth Nardout-Lafarge (dir.), Interférences. Autour de Pierre L'Hérault, Udine, Forum, coll. «Études du Centre de culture canadienne», 2010, p. 41-59.

+ LAVOIE, Sylvain, «Du regard tragique à la langue de pierre», Alessandra Ferraro et Élisabeth Nardout-Lafarge (dir.), Interférences. Autour de Pierre L'Hérault, Udine, Forum, coll. «Études du Centre de culture canadienne», 2010, p. 61-73.

+ MATIĆ, Ljiljana, «Daniel Danis, poète de la nature du Québec», Annuaire de la faculté de philosophie, Novi Sad, vol. XXXV, n 2, 2010, p. 57-68.

+ RYNGAERT, Jean-Pierre, «Dilatation du temps de l'énonciation et épaississement des phénomènes de perception", Catherine Naugrette (dir.), Le contemporain en scène. Volume II, Paris, L'Harmattan, 2011, p. 77-84.

+ NUTTING, Stéphanie, «L'animal au théâtre ou la mise en jeu d'une altérité radicale», L'Annuaire théâtral, nos 50-51, automne 2011-printemps 2012, p. 155-169.

\section{Commentaires parus dans des périodiques}

+ CANTIN, David, «Empierrement de la parole et de l'art», Le Devoir, 24 mars 2001, p. C3.

+ POULIOT, Sophie, «L'art de prendre la parole», Le Devoir, 26 avril 2003, p. G7.

\section{E. Comptes rendus et articles de presse ${ }^{4}$}

\section{1) Celle-là}

+ LAFORGE, Christiane, «Une tragédie poétique de Daniel Danis», Le Quotidien, 26 septembre 1992, p. 16.

+ BOUlANGER, Luc, «Daniel Danis. Parole d'honneur», Voir Montréal, du 7 au 13 janvier 1993, p. 16.

+ LÉVESQUE, Robert, «Une autre maison cassée. Celle-là», Le Devoir, 15 janvier 1993, p. B4.

+ BEAUNOYER, Jean, "À l’ESPACE GO. Daniel Danis mal servi», La Presse, 17 janvier 1993, p. B7.

+ BEAUNOYER, Jean, «Une période de bouillonnement», La Presse, 18 janvier 1993, p. A11.

+ BOULANGER, Luc, «Celle-là. Celle qui va», Voir Montréal, 28 janvier au 3 février 1993, p. 31.

+ JUBINVILLE, Yves, "Une question de temps», Spirale, n 123, avril 1993, p. 17.

+ BÉRARD, Sylvie, «L'appel du corps», Lettres québécoises, nº 71, automne 1993, p. 49-50.

+ BELZIL, Patricia, «Celle-là», Jeu. Revue de thêâtre, nº 66, 1993, p. 145-150.

+ GUAY, Christian, "La mise en espace de Celle-là», Jeu. Revue de théâtre, n 70, 1994, p. 110-119.

4 Sauf exception, les comptes rendus et les articles de presse uniquement parus en ligne n'ont pas été recensés. 
+ LÉVESQUE, Robert, «Daniel Danis mis en scène par Alain Françon», Le Devoir, 17 janvier 1995, p. B8.

+ SOLIS, René, "Celle-là, la sorcière du Québec», Libération, 21 janvier 1995, p. 32.

+ COPPERMANN, Annie, "Celle-là, de Daniel Danis. Comme une boule dans l'estomac», Les Échos, 24 janvier 1995, p. 46.

+ SALINO, Brigitte, "Celle-là de Daniel Danis», Le Monde, 24 janvier 1995, p. 30.

+ [ANONYME], "Celle-là, un mélodrame à la mode du Québec», La Tribune, 31 janvier 1995, [s. p.].

+ [ANONYME], «Deux Québécois honorés», Le Journal de Montréal, 2 juillet 1995, p. 37.

+ SAINT-HILAIRE, Jean, «Daniel Danis. La douleur de l'abandon», Le Soleil, 23 octobre 1999, p. D8.

+ SAINT-HILAIRE, Jean, «Critique: Du meilleur et du perfectible. Gill Champagne et Jean Hazel réaffirment leur hardiesse dans Celle-là», Le Soleil, 28 octobre 1999, p. C14.

+ CANTIN, David, «De corps et de parole», Le Devoir, 29 octobre 1999, p. B8.

+ ADAMO, Ghania, "À Am Stram Gram, un mélo québécois sombre par excès de réalisme», Le Temps, $\mathrm{n}^{\circ}$ 620, 14 février 2000, [s. p.].

+ LADOUCEUR, Louise, "Des tableaux d'une rare intensité: Celle-là», Jeu. Revue de théâtre, $n^{\circ}$ 94, 2000, p. 55-56.

+ PELLETIER, Denise, «Benoît Lagrandeur assure la mise en scène. La Rubrique présente Celle-là de Daniel Danis », Le Quotidien, 25 janvier 2001, p. 19.

+ PELLETIER, Denise, «Celle-là, de Daniel Danis. La Rubrique respecte le style unique de l'auteur», Le Quotidien, 3 février 2001, p. 24.

+ BARRIÈRE, Caroline, "Naviguer en eaux troubles avec Celle-là», Le Droit, 14 juin 2001, p. 35.

+ BARRIĖRE, Caroline, «Daniel Danis servi qu'à demi avec Celle-là», Le Droit, 16 juin 2001, p. 42.

+ PELLETIER, Denise, «Traduction en italien de sa pièce. L'auteur travaille avec Joia Costa», Progrès-dimanche, 17 juin 2001, p. B5.

+ ST-JACQUES, Sylvie, "Celle-là en anglais», La Presse, 18 septembre 2006, p. ARTS ET SPECTACLES 7.

+ [ANONYME], «Daniel Danis par Guy Lenoir», Sud Ouest, 26 juin 2007, p. 15.

+ GUAY, Hervé, "Un Danis "trash"», Le Devoir, 18 septembre 2007, p. B7.

+ LATAPY, Serge, «Famille décomposée», Sud Ouest, 14 février 2008, p. 18.

+ MAKEREEL, Catherine, «Du Daniel Danis aux Martyrs. Un beau, très beau gâchis», Le Soir, 16 novembre 2010, p. 44.

\section{2) Cendres de cailloux}

+ PAVLOVIC, Diane, «Détruire, dit-elle», Voir Montréal, 11 au 17 novembre 1993, p. 35.

+ DAVID, Gilbert, «Isabelle Miquelon en quête d'absolu. La comédienne crée le personnage de Shirley dans la plus récente pièce de Daniel Danis, Cendres de cailloux», Le Devoir, 20 novembre 1993, p. C6.

+ BEAUNOYER, Jean, "Cendres de cailloux. Une autre création québécoise marquante», La Presse, 21 novembre 1993, p. B9.

+ LÉVESQUE, Robert, «Un mauvais quart d'heure sur la planète», Le Devoir, 22 novembre 1993, p. B8.

+ BOULANGER, Luc, «Cendres de cailloux. Pierre qui roule», Voir Montréal, 25 novembre au $1^{\text {er }}$ décembre 1993, p. 33. 
+ BÉRARD, Sylvie, «L'appel du corps», Lettres québécoises, n 71, automne 1993, p. 49-50.

+ SAINT-HILAIRE, Jean, «Cendres de cailloux. Shirley, l'amazone de force de Linda Laplante», Le Soleil, 8 janvier 1994, p. D3.

+ SAINT-HILAIRE, Jean, "Cendres de cailloux au Périscope. La froide mémoire de la pierre», Le Soleil, 13 janvier 1994, p. C3.

+ CHAREST, Rémy, «L'un enchante, l'autre moins... Un Molière un peu boiteux et un merveilleux Danis", Le Devoir, 14 janvier 1994, p. B6.

+ SAINT-HILAIRE, Jean, «Entrevue avec l'auteur de Cendres de cailloux. Daniel Danis, un dramaturge sur la piste du sacré», Le Soleil, 20 janvier 1994, p. C3.

+ L'HÉRAULT, Pierre, «Théâtre de l'intolérable», Spirale, no 131, mars 1994, p. 14-15.

+ SAINT-HILAIRE, Jean, «Cendres de cailloux: vous avez vu du changement, vous?», Le Soleil, 29 mai 1994, p. B2.

+ BEAUNOYER, Jean, "Carrefour 94/Un engouement qui ne se dément pas pour Revolver», La Presse, 2 juin 1994, p. D11.

+ SAINT-HILAIRE, Jean, "Au Périscope du 23 novembre au 3 décembre. Cendres de cailloux est de retour», Le Soleil, 19 novembre 1994, p. G8.

+ BELZIL, Patricia, «Le rituel de la vie: Cendres de cailloux», Jeu. Revue de thêâtre, nº 70, 1994, p. 98-104.

+ JOANISSE, Bernard, «Daniel Danis et William Shakespeare au Saguenay », Jeu. Revue de thêâtre, nº 70, 1994, p. 105-109.

+ JOANISSE, Marc-André, «L'amour et la force de l'imaginaire», Le Droit, 21 janvier 1995, p. A4.

+ DEMERS, Edgard, «Cendres de cailloux au Théâtre de l'île. Du thêâtre pénétrant jusqu'aux entrailles», Le Droit, 30 janvier 1995, p. 16.

+ L'HÉRAULT, Pierre, «En bref» [Cendres de cailloux], Spirale, n 140, mars 1995, p. 7.

+ BELZIL, Patricia et Philip WICKHAM, «Entre quat'zyeux: les 20 jours du thêâtre à risque - 5e édition", Jeu. Revue de théâtre, n 75, 1995, p. 10-24.

+ [ANONYME], «Rendez-vous à l'Utopie», Sud Ouest, 3 mars 1997, p. D.

+ [ANONYME], «Rendez-vous à Paris», Sud Ouest, 14 avril 1997, p. C.

+ MEREUZE, Didier, «L'amour de Daniel Danis sans eau de rose. Théâtre. Cendres de cailloux, du Québécois Daniel Danis, au Théâtre Gérard-Philipe se révèle un coup de maître. Juste au cœur, droit au ventre», La Croix, 11 mai 2000, p. 16 (Culture).

+ SAINT-PIERRE, Christian, «Quand la mort danse avec la vie: Cendres de cailloux de Daniel Danis », Jeu. Revue de thêâtre, n 97, 2000, p. 63-67.

+ L'HÉRAULT, Pierre, "Quelques textes porteurs de la dernière décennie», Jeu. Revue de théâtre, no 100, 2001, p. 127-139.

+ [ANONYME], «Cendres de cailloux: des histoires qui nous concernent», Le Progrès, 8 décembre 2003, p. 7.

+ [ANONYME], «Les douleurs intérieures de Danis», Le Progrès, 8 décembre 2003, p. 12.

+ [ANONYME], "Cendres de cailloux. Vincent Goetals met en scène un jeune auteur québécois», Ouest-France, 14 décembre 2003, [s. p.].

+ BIGOT, Pierre, «Désespoir au fond des bois...», Ouest-France, 19 décembre 2003, p. 12.

+ [ANONYME], «Le feu du théâtre sous les Cendres de cailloux», Le Télégramme, 5 janvier 2004, [s. p.].

+ [ANONYME], "Cendres de cailloux ravive la flamme des sentiments», Le Télégramme, 21 janvier 2004, [s. p.]. 
+ [ANONYME], «Goethals revient avec une pièce du Québécois Daniel Danis. Cendres de cailloux le 27 au Carré», Ouest-France, 21 janvier 2004, p. 10.

+ CH. M., «Cendres de cailloux: bouleversant!», Le Progrès, 25 janvier 2004, p. 10.

+ [ANONYME], «Cendres de cailloux embrase le Carré», Le Télégramme, 29 janvier 2004, [s. p.].

+ [ANONYME], «La pièce du québécois Daniel Danis jouée par le "Théâtre en Scène". Larmes, cendres et cailloux au Carré», Ouest-France, 29 janvier 2004, p. 11.

+ [ANONYME], «Ā partir de demain à l'Idéal à Tourcoing. Cendres de cailloux», La Voix du Nord, 3 novembre 2004, [s. p.].

+ [ANONYME], «Cendres de cailloux, de Daniel Danis à l'Idéal de Tourcoing jusqu'au 14 novembre. L'émotion d'une rivière de mots», La Voix du Nord, 7 novembre 2004, [s. p.].

+ [ANONYME], «Fantômes brûlants», Sud Ouest, 17 novembre 2004, p. 21.

+ [ANONYME], «Vincent Goeathals, sourcier de la langue, poète des planches », Le Soir, $1^{\text {er }}$ décembre 2004, [s. p.].

+ [ANONYME], «L'Espal recueille les Cendres de cailloux de Danis», Ouest-France, 27 février 2005, p. 10.

+ [ANONYME], «Les braises de la vie», 24 Heures, 27 février 2009, p. 4.

\section{3) Le chant du Dire-Dire}

+ BERNATCHEZ, Raymond, «Le chant du Dire-Dire: pour le dépaysement», La Presse, 25 avril 1998, p. D5.

+ BAILLARGEON, Stéphane, "La voix intérieure», Le Devoir, Les Actualités, 28 avril 1998, p. A1.

+ BERNATCHEZ, Raymond, «Sauter à pieds joints dans l'univers de Daniel Danis», La Presse, 2 mai 1998, p. D15.

+ GUAY, Hervé, «De l'âme et du sens», Le Devoir, 6 mai 1998, p. B7 (Culture).

+ GODIN, Diane, "Paradoxe», Jeu. Revue de thêâtre, nº 88, 1998, p. 168-171.

+ SOLIS, René, «Théâtre. Alain Françon tombe dans les excès du naturalisme à la québécoise. Parler pour ne rien Dire-Dire. Le chant du Dire-Dire, de Daniel Danis, m.e.s. d'Alain Françon, Thêâtre national de la Colline. Jusqu'au 23 octobre.», Libération, 18 septembre 1999, p. 32.

+ LIBAN, Laurence, «Oratorio pour une vierge muette», L'Express, 23 septembre 1999, p. 114 (Culture).

+ P[resse] C[anadienne], «Avec Le chant du Dire-Dire, Daniel Danis connaît un beau succès à Paris», Le Quotidien, 27 septembre 1999, p. 7 (Arts et spectacles).

+ PERRIER, Jean-Louis, «L'éblouissement du dire-dire, machine de thêâtre poétique de Daniel Danis», Le Monde, 27 septembre 1999, p. 28.

+ FERNEY, Frédéric, "Admirable», Le Figaro, 28 septembre 1999, p. 28.

+ FERNEY, Frédéric, "Le chant du Dire-Dire», Le Point, n 1411, 1 ${ }^{\mathrm{er}}$ octobre 1999, p. 145.

+ MEUREUZE, Didier, «L'inoubliable Chant du Dire-Dire», La Croix, 20 novembre 1999, p. 19.

+ BAILLARGEON, Stéphane, «Willkommen, Herr Danis! Le chant du Dire-Dire en allemand à Berlin", Le Devoir, 8 mars 2000, p. B8 (Culture).

+ DUMAS, Ėve, «Le chant du redire», La Presse, 4 mars 2002, p. C6.

+ SAINT-HILAIRE, Jean, «Le chant du Dire-Dire, au Périscope», Le Soleil, 5 mars 2002, p. B4 (Arts et vie).

+ CANTIN, David, «Pour la suite du monde», Le Devoir, 7 mars 2002, p. B8 (Culture).

+ SAINT-HILAIRE, Jean, «Le chant du Dire-Dire: La robe de la fille du tonnerre», Le Soleil, 7 mars 2002, p. B5 (Arts et vie). 
+ FRICHE, Michèle, "Les images telluriques du Chant du dire-dire», Le Soir, 10 novembre 2005, [s. p.].

+ MAKEREEL, Catherine, «Tempête dans un familistère», Le Soir, 25 novembre 2005, p. 34.

+ [ANONYME], «Le chant du Dire-Dire: soins d'amour», Ouest-France, 11 décembre 2007, p. 13.

+ VOYER, Patrick, «Les mots de Daniel Danis joués à l'Espace René-Provost», Transcontinental, 4 octobre 2008, p. 26 (Arts et spectacles).

+ LEMERY, Marthe, «De l'urgence de prendre la parole», Le Droit, 9 octobre 2008, p. 35 (Arts et spectacles).

+ LEMERY, Marthe, «L'harmonie pour veiller le silence», Le Droit, 15 octobre 2008, p. A8 (Arts et spectacles).

+ H. E., «Le chant du Dire-Dire: charnelle histoire de fratrie», La Nouvelle République, 11 novembre 2009, p. 6.

+ PROULX, Mélissa, «Marc Béland: Ainsi soit-il», Voir, 20 septembre 2012, en ligne: http://voir. ca/scene/2012/09/20/marc-beland-ainsi-soit-il [page consultée le 11 novembre 2014].

+ SIAG, Jean, «Le chant du Dire-Dire: les brebis sacrifiées à l'autel», La Presse, 28 septembre 2012, p. 7 (Arts et spectacles).

+ CADIEUX, Alexandre, «Les insolubles», Le Devoir, $1^{\text {er }}$ octobre 2012, p. B8 (Culture).

+ DAVID, Gilbert, "À portée de voix», Spirale, n 243, hiver 2013, p. 77-79.

+ HOUDE, Isabelle, "Au théâtre comme à l'église», Le Soleil, 1 mars 2014, p. A14 (Arts magazine).

+ HOUDE, Isabelle, «La fratrie au cœur du Chant du Dire-Dire», Le Soleil, 5 mars 2014, p. 34 (Arts et spectacles).

+ LAVOIE, Sylvain, "Le chant du Dire-Dire: en(tre) deux temps», Jeu. Revue de théâtre, 5 mars 2014, en ligne: http://www.revuejeu.org/critiques/sylvain-lavoie/le-chant-du-dire-dire-entredeux-temps [page consultée le 11 novembre 2014].

+ VIKLUND, Andrea, «Le chant du Dire-Dire/La pièce», le Mimésis. Productions théâtrales, [s. d.], en ligne: http://lemimesis.com/historique/la-piece/[page consultée le 11 novembre 2014].

\section{4) L'enfant lunaire}

+ DESLOGES, Josianne, "Daniel Danis et Gob Sqad au prochain Mois Multi», Le Soleil, 12 décembre 2012, p. 39 (Arts et spectacles).

+ DESLOGES, Josianne, "Théâtre intime sans acteur», Le Soleil, 30 janvier 2013, p. 29 (Arts et spectacles).

\section{5) e. Roman-dit}

+ [ANONYME], "Ā La Colline, e, le récit théâtral de Daniel Danis inspiré par la chanson de geste», AFP Infos françaises, 28 janvier 2005, [s. p.] (Art/Culture/Médias).

+ DARGE, Fabienne, «e, la légende qui mène un bébé prédestiné de l'exode à l'exil», Le Monde, 4 février 2005, p. 31 (Culture).

+ DOLBEC, Michel, «Une nouvelle pièce de Daniel Danis est créée à Paris», La Presse canadienne, 7 février 2005, [s. p.] (Arts et spectacles).

+ RIOUX, Christian, "La chanson des déportés», Le Devoir, 7 févier 2005, p. B8 (Culture).

+ COPPERMAN, Annie, "Le chant des exilés», Les Échos, 8 février 2005, p. 17.

+ PARÉ, Yvon, «Daniel Danis présente e», Progrès-dimanche, 9 janvier 2005, p. B15 (Arts-Télé).

+ MIGLIORINI, Robert, «Une épopée aux frontières du monde», La Croix, 10 février 2005, p. 17 (Culture). 
+ HELIOT, Armelle, «e de Daniel Danis. Une déception», Le Figaro, 21 février 2005, p. 21.

\section{6) $K i w i$}

+ DESLOGES, Josianne, «Le ciné-théâtre de Daniel Danis à Avignon: un spectacle filmé en infrarouge», Le Soleil, 24 juillet 2008, p. 32 (Arts et spectacles).

+ CÔTÉ, Daniel, «Kiwi de Daniel Danis: une vision italo-québécoise», Le Quotidien, 19 septembre 2008, p. 12 (Actualités).

+ SAINT-HILAIRE, Jean. "Kiwi, à la salle multi de Méduse: la jeunesse des bas-fonds», Le Soleil, 22 novembre 2008, p. 35 (Arts et spectacles).

+ SIAG, Jean, «Le récit fait cinéma», La Presse, 22 novembre 2008, p. 18 (Arts et spectacles).

+ SAINT-HILAIRE, Jean. «Kiwi de Daniel Danis: lumière des catacombes", Le Soleil, 25 novembre 2008, p. 39 (Arts et spectacles).

+ BOUDREAULT, Françoise, "Transity: collaboration italo-québécoise à ManiganSes», Jeu. Revue de théâtre, nº 130, 2009, p. 144-146.

+ BERTIN, Raymond, "De l'audace et de l'inédit: les Coups de théâtre 2008», Jeu. Revue de théâtre, no 131, 2009, p. 58-62.

+ LE SCANFF, Yvon, «Théâtre», Études 12, t. 411, 2009, p. 674-675.

+ [ANONYME], «Les objets, vedettes d'un conte moderne», Ouest-France, 21 septembre 2012, [s. p.].

+ BERTIN, Raymond, «La parole aux marionnettistes», Jeu. Revue de thêâtre, nº 143, 2012, p. 56-67.

+ BOUDREAULT, Françoise, «Présence et dynamisme de la marionnette au Saguenay-LacSaint-Jean", Jeu. Revue de théâtre, nº 143, 2012, p. 100-109.

\section{7) Le langue-à-langue des chiens de roche}

+ PELLETIER, Denise, «La langue des chiens de roche», Le Quotidien, $1^{\text {er }}$ avril 1999, p. 28 (Arts et spectacles).

+ RIOUX, Christian, «Sur les traces de Jouvet. Daniel Danis joue à la Comédie-Française dans Le langue-à-langue des chiens de roche», Le Devoir, 21 novembre 2000, p. B8 (Culture).

+ BAILLARGEON, Stéphane, «Le yeux-à-yeux du Dire-Dire», Le Devoir, 6 janvier 2001, p. C3 (Les arts).

+ COUËLlE, Jennifer, «Chiens et baisers», La Presse, 6 janvier 2001, p. D9.

+ COUËLlE, Jennifer, «Une île tragique», La Presse, 14 janvier 2001, p. B9.

+ POULIOT, Sophie, «Au secours d'amour!», Le Devoir, 16 janvier 2001, p. B8 (Culture).

+ DESCÔTEAUX, Josée, "Comme des boules dans la gorge. Le langue-à-langue des chiens de roche», Le Droit, 17 février 2001, p. A12 (Les arts).

+ CÔTÉ, Christian, «Le langue-à-langue des chiens de roche: la langue à vif», Le Droit, 23 février 2001, p. 42 (Les arts).

+ PELLETIER, Denise, «Le langue-à-langue des chiens de roche. Daniel Danis joué à la ComédieFrançaise», Progrès-dimanche, 17 juin 2001, p. B5 (Arts et société).

+ LAFARGUE, André, «Le langue-à-langue des chiens de roche: une jeunesse aux abois», Le Parisien, 4 décembre 2001, p. 30.

+ PINTE, Jean-Louis, «Le langue-à-langue des chiens de roche au Vieux-Colombier: un méchant grand parlage», Le Figaro, 5 décembre 2001, p. 69.

+ FERNEY, Frédéric, "Le langue-à-langue des chiens de roche de Daniel Danis: l'humide et le sauvage», Le Figaro, 7 décembre 2001, p. 32. 
+ LAZARIDĖS, Alexandre, "Île à la dérive, avec chiens : Le langue-à-langue des chiens de roche», Jeu. Revue de théâtre, n 99, 2001, p. 11-14.

+ MASSOUTRE, Guylaine, "Coeur de roc: le lyrisme ardent de Daniel Danis», Jeu. Revue de théâtre, no 99, 2001, p. 15-19.

+ [ANONYME], «Communauté à la dérive au Trident», Québec Express, 30 octobre 2004, [s. p.] (Arts et cultures).

+ PORTER, Isabelle, «Daniel Danis, l'incontournable», Le Devoir, 30 octobre 2004, p. E4 (Culture).

+ SAINT-HILAIRE, Jean, «Paroles de marginaux», Le Soleil, 2 novembre 2004, p. B1 (Arts et vie).

+ SAINT-HILAIRE, Jean, "Critique: Le langue-à-langue des chiens de roche», Le Soleil, 6 novembre 2004, p. C11 (Arts et spectacles).

+ BOUCHARD, Jacqueline, «Langue de roche et autres dialectes», Spirale, $\mathrm{n}^{\circ}$ 201, marsavril 2005, p. 56-57.

+ BOUCHARD, Geneviève, "C'était un spectacle vraiment extraordinaire! Le langue-à-langue des chiens de roche vole la vedette», Le Soleil, 29 novembre 2005, p. B5 (Arts et vie).

+ PLOURDE, Élizabeth, «La clameur des chiens de roche: Le langue-à-langue des chiens de roche», Jeu. Revue de théâtre, n 115, 2005, p. 71-75.

+ MAKEREEL, Catherine, "Langue-à-langue avec les Québécois», Le Soir, 18 septembre 2009, p. 29.

+ POULIOT, Sophie, "Le langue-à-langue des chiens de roche», Le Devoir, 20 janvier 2011, p. 4 (L'Agenda).

\section{8) Mille anonymes}

+ BLACKBURN, Roger, "La pièce de Daniel Danis en grande première à Québec», Le Progrèsdimanche, $1^{\mathrm{er}}$ mai 2011, p. 50 (Arts).

+ MOREAULT, Éric, «Mille anonymes: lire entre les lignes», Le Soleil, 26 mai 2011, p. 44 (Arts et spectacles).

+ DEMERS, Véronique, «Dans la parole fragmentaire de Mille anonymes», Québec hebdo, 27 mai 2011, [s. p.] (Spectacles).

+ SIAG, Jean, «Laisser sa trace», La Presse, 30 mai 2011, p. ARTS ET SPECTACLES 5.

+ COUTURE, Philippe, «La nature a horreur du vide», Le Devoir, $1^{\mathrm{er}}$ juin 2011, p. B10 (Culture).

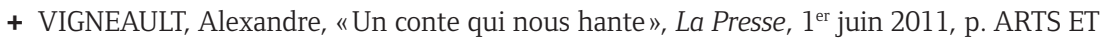
SPECTACLES 4.

+ DAVID, Gilbert, «Conte et parabole hallucinatoire», Spirale, n 238, automne 2011, p. 84-86.

\section{9) Naufragium}

+ BARRIËRE, Caroline, «La radio comme si vous y étiez», Le Droit, 13 mars 1999, p. A3 (Arts et spectacles).

+ VAÏS, Michel, «Petite cocasserie: Naufragium», Jeu. Revue de thêâtre, n 93, 1999, p.161-162.

\section{$10)$ Les nuages de terre}

+ DOLBEC, Michel, «Nuages de terre, la plus aboutie des expériences de coproduction québécoafricaine», La Presse, 27 septembre 1994, p. A18 (Arts et spectacles).

+ DOLBEC, Michel, «Les Deux Mondes coproduisent avec l'Afrique», Le Devoir, 27 septembre 1994, p. B7 (Culture).

+ SCHMITT, Olivier, «Le onzième festival des Francophonies en Limousin: les insuffisances de l'hybridation", Le Monde, 29 septembre 1994, p. 19. 
+ RIOUX, Christian, «Les nuages du multiculturalisme», Le Devoir, 11 octobre 1994, p. B8 (Culture).

+ VIGEANT, Louise, "Le désir et le plaisir de la cocréation: Ki-Yi M’Bock et Les Deux Mondes», Jeu. Revue de théâtre, nº 73, 1994, p. 126-131.

+ WICKHAM, Philip, «Les nuages de terre», Jeu. Revue de thêâtre, nº 78, 1996, p. 122.

\section{L Le pont de pierres et la peau d'images}

+ DOLBEC, Michel, «Daniel Danis de retour à Paris», La Presse, 10 mars 1997, p. A21 (Arts et spectacles).

+ DOLBEC, Michel, «Pont de pierres...», Le Soleil, 11 mars 1997, p. C2 (Arts et spectacles).

\section{2 ) La scaphandrière}

+ MOREAUlT, Éric, «Retrouver l'enfance perdue», Le Soleil, 5 novembre 2012, p. 28 (Arts et spectacles).

+ JOANNY-FURTIN, Michel, «La scaphandrière émerge à l'Outremont pendant trois jours», L'Express d'Outremont, 15 novembre 2012, p. 5.

+ LAPOINTE, Josée, "Olivier Letellier et Daniel Danis dans La scaphandrière: savoir-faire image», La Presse, 17 novembre 2012, p. 17 (Arts et spectacles).

+ MOREAULT, Éric, «La scaphandrière: superbe plongée dans l'âme», Le Soleil, 23 novembre 2012, p. 33 (Arts et spectacles).

+ BERTIN, Raymond, «Les coups de théâtre, laboratoire d'expérimentation», Lurelu, vol. 35, n² 2 , automne 2012, p. 9-10.

\section{3 ) Sous un ciel de chamaille}

+ TURCOT, Geneviève. «Histoire d'eau et de guerre», Le Droit, 18 mai 2007, p. 39 (Arts).

\section{4 ) Terre océane}

+ BEAUNOYER, Jean, "La quarantaine et ses questions», La Presse, 22 octobre 2007, p. ARTS ET SPECTACLES 6.

+ GUAY, Hervé, «Le retour à la terre», Le Devoir, 29 octobre 2007, p. B8 (Culture).

+ BEAUNOYER, Jean. «Pour apprivoiser la mort», La Presse, 30 octobre 2007, p. 5 (Arts et spectacles).

+ SAINT-HILAIRE, Jean. «Terre océane, au Trident: le messager venu du passé», Le Soleil, 19 janvier 2008, p. A14.

+ SAINT-HILAIRE, Jean. «Terre océane: un cérémonial coloré et d'une magnifique unité», Le Soleil, 28 janvier 2008, p. A2.

+ LAVOIE, Sylvain, «Partitions de deuil», Spirale, n 219, mars-avril 2008, p. 56.

+ BERTIN, Raymond, «Le réveil du père», Jeu. Revue de théâtre, nº 126, 2008, p. 12-15.

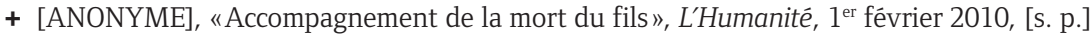
(Culture).

+ CHEVILLEY, Philippe, "Terre océane de Daniel Danis: un requiem inabouti», Les Échos, 2 avril 2010, n 20649, p. 15.

+ SALINO, Brigitte, "Au cœur de la Terre océane, le beau récit d'un enfant qui meurt», Le Monde, 3 avril 2010, p. 24 (Culture). 


\section{5) Yukie}

+ MOREAUlT, Éric, «Yukie de Daniel Danis: Tokyo P.Q.», Le Soleil, 25 mai 2010, p. 33 (Arts et spectacles).

+ CÔTÉ, Martine, «La science des rêves», Voir Québec, 3 juin 2010, en ligne: http://voir.ca/ scene/2010/06/03/daniel-danis-la-science-des-reves [page consultée le 11 novembre 2014].

+ MOREAULT, Éric, «Les triplettes de l'île», Le Soleil, 4 juin 2010, p. 40 (Arts et spectacles).

+ NICOLAS, Sylvie, «La peau de l'image», Le Devoir, 8 juin 2010, p. B10 (Culture).

\section{F. Sur et autour de $1^{\prime}$ auteur}

1) Articles

+ PELLETIER, Denise, «Daniel Danis hésite à se considérer comme un auteur dramatique», Progrès-dimanche, 9 mai 1999, p. B1 (Arts et sociétê).

+ PELLETIER, Denise, «Daniel Danis. Une "vocation" née dès l'âge de huit ans», Progrèsdimanche, 9 mai 1999, p. B3 (Arts et société).

+ SAINT-HILAIRE, Jean, «Daniel Danis international», Le Soleil, Primeurs, 23 octobre 1999, p. D8.

+ [ANONYME], «Comédie-Française: Daniel Danis, troisième auteur québécois joué en quatre ans», AFP Info françaises, 22 novembre 2001, [s. p.].

+ LEONARDINI, Jean-Pierre, "Ces temps-ci, il n'est bon bec que du Québec», L'Humanité, 17 décembre 2001, p. 21.

+ PELLETIER, Denise, «Chevalier des arts et des lettres de la République française. L'auteur Daniel Danis décoré», Le Quotidien, 7 juin 2003, p. 5.

+ PERRIER, Jean-Louis, «Daniel Danis, le théâtre en transes», Le Monde, 17 novembre 2003, p. 22 (Culture).

+ PARÉ, Yvon, «Daniel Danis ne comprend pas», Progrès-dimanche, 3 octobre 2004, p. B3 (Arts-Télé).

+ SAINT-HILAIRE, Jean, "Parole de marginaux», Le Soleil, 2 novembre 2004, p. B1 (Arts et vie).

+ PARÉ, Yvon, «Daniel Danis en voie de réaliser son rêve», Progrès-dimanche, 9 mai 2005, p. B13 (Arts-Télé).

+ SAINT-HILAIRE, Jean, «Une parole singulière et son passeur», Le Soleil, $1^{\text {er }}$ juin 2005, p. B5 (Arts et vie).

+ VAÏS, Michel, «Boudés au Québec, aimés en France?», Jeu. Revue de théâtre, n 117, 2005, p. 128-135.

+ DOYON, Frédérique, "L'écriture théâtrale en trois dimensions», Le Devoir, 17 juillet 2007, p. B8 (Culture).

+ BÉLAIR, Michel, "À l'extrémité du narratif», Le Devoir, 23 octobre 2007, p. B9 (Culture).

+ LAFORGE, Christiane, «Daniel Danis doublement heureux», Le Quotidien, 28 novembre 2007, p. 28 (Arts).

+ [ANONYME], «Daniel Danis à la Comédie-Française», Le Soleil, 30 mai 2011, p. E5 (Extra).

\section{2) É changes et entrevues}

+ RENAUDE, Noëlle et DURIF, Eugène, "Éclats d'une conversation avec Daniel Danis», Les Cahiers de Prospero, $\mathrm{n}^{\circ}$ 1, 1993, p. 32-35.

+ SAINT-HILAIRE, Jean. «Entrevue avec l'auteur de Cendres de cailloux», Le Soleil, 20 janvier 1994, p. C3 (Arts et spectacles). 
+ MIGIORINI, Robert, "À la recherche de l'âme par le corps. Pour Daniel Danis, l'auteur de la pièce Le chant du Dire-Dire, il faut passer aujourd'hui par des lieux désacralisés pour entendre parler du ciel et de la terre. Entretien. Daniel Danis, Auteur du Chant du dire-dire.», La Croix, 20 septembre 1999, p. 19 (Culture).

+ M. F., «Danis écrit: "parce que le corps criait"», Le Soir, 1 1er décembre 2004.

+ HÉMAIN, Laure et Olivia GOTANĖGRE, «e, un roman-dit. D'un exode à l'autre: une histoire en boucle. Entretien avec Daniel Danis", janvier 2005, en ligne: http://www.colline.fr/sites/ default/files/revue_electronique/02-daniel-danis. pdf [page consultée le 28 avril 2014].

+ DANIS, Daniel, "“Qu'est-ce que ça mange, un dialogue?..." ", dialogue avec Alain Françon, Jean-Pierre Ryngaert et Anne Contensou, Études théâtrales, n³3, 2005, p. 181-187.

+ VAÏS, Michel, «Rêver la guerre: entretien avec Daniel Danis», Jeu. Revue de thêâtre, nº 117, 2005, p. 125-135.

+ SAINT-PIERRE, Christian, «Daniel Danis: la métamorphose», Voir Montréal, 6 novembre 2008, en ligne: http://voir.ca/scene/2008/11/06/daniel-danis-la-metamorphose/[page consultée le 11 novembre 2014].

+ DESLOGES, Josianne, «Ballet de voix immortelles», Le Soleil, 21 mai 2011, p. A6 (Arts magazine).

+ FESTIVAL TRANSAMÉRIQUES, «"La mémoire intime au théâtre”, table ronde avec Daniel Danis et Marie Brassard", rencontre animée par Martin Faucher, Vidéos de théâtre sur theatre-video. net, 69 min 15s, 2011, en ligne: http://www.theatre-video.net/video/La-memoire-intimeau-theatre-table-ronde-avec-Daniel-Danis-et-Marie-Brassard [page consultée le 11 novembre 2014].

+ ROBERGE, Josianne, «Entrevue avec Daniel Danis: L'enfant lunaire», Recto verso, Mois Multi 14, 5 min 30s, 2013, en ligne: http://mmrectoverso.org/fr/mois-multi/editions-precedentes/ mois-multi-14/videos-entrevues/daniel-danis-lenfant-lunaire/[page consultée le 11 novembre 2014].

\section{3) Affiches}

+ Celle-là, mise en scène de Louise Laprade, Montréal, ESPACE GO, 1993 (janvier).

+ Cendres de cailloux, mise en scène de Louise Laprade, Montréal, ESPACE GO, 1993 (novembre).

+ Les nuages de terre, mise en scène de Daniel Meilleur et Wêrê-Wêrê Liking, Montréal, Théâtre Les Deux Mondes et Ki-Yi M’Bock, 1994 (juillet).

+ Celle-là, mise en scène de Benoît Lagrandeur, Jonquière, Thêâtre de la Rubrique, 2001 (janvier).

+ Le langue-à-langue des chiens de roche, mise en scène de René Richard Cyr, Montréal, Théâtre d'Aujourd'hui, 2001 (janvier).

+ Le langue-à-langue des chiens de roche, mise en scène de Gill Champagne, Québec, Thêâtre du Trident, 2004 (novembre).

+ Terre océane, mise en scène de Gill Champagne, Montréal, Théâtre de Quat'Sous, Théâtre du Trident et Logomotive Théâtre, 2007 (octobre).

+ Les sens [de Michel Marc Bouchard, Sylvie Bouchard, Daniel Danis, Jean-Rock Gaudreault, Larry Tremblay, Pierre-Michel Tremblay], mise en scène de Benoît Lagrandeur, Jonquière, Théâtre de la Rubrique, 2011 (janvier).

\section{4) Program mes}

+ Celle-là, mise en scène de Louise Laprade, Montréal, ESPACE GO, 1993 (janvier). 
+ Cendres de cailloux, mise en scène de Dominick Bédard, Jonquière, Théâtre de la Rubrique, 1993 (octobre).

+ Cendres de cailloux, mise en scène de Louise Laprade, Montréal, ESPACE GO, 1993 (novembre).

+ Le chant du Dire-Dire, mise en scène de René Richard Cyr, Montréal, ESPACE GO, 1998 (avril).

+ Celle-là, mise en scène de Benoît Lagrandeur, Jonquière, Théâtre de la Rubrique, 2001 (janvier).

+ Le langue-à-langue des chiens de roche, mise en scène de René Richard Cyr, Montréal, Théâtre d'Aujourd'hui, 2001 (janvier).

+ Le langue-à-langue des chiens de roche, mise en scène de Gill Champagne, Québec, Théâtre du Trident, 2004 (novembre).

+ That Woman, mise en scène d'Emma Tibaldo, Montréal, Talisman Theatre, 2006 (septembre).

+ Sommeil et rouge, performance poétique [adaptation du poème chinois «Chant de l'éternel regret» de Po Kiu-yi], mise en œuvre de Daniel Danis, Montréal, Usine C, 2006.

+ That Woman, mise en scène d'Emma Tibaldo, Montréal, Talisman Theatre et Infinitheatre, 2007 (septembre).

+ Terre océane, mise en scène de Gill Champagne, Montréal, coproduction Théâtre de Quat'Sous, Théâtre du Trident, Logomotive Théâtre (France) et Compagnie Daniel Danis, arts/sciences, Montréal, Théâtre d'Aujourd'hui, 2007 (octobre).

+ Le chant du Dire-Dire, mise en scène d'Anne Marie Riel, Gatineau, Espace René-Prévost, 2008 (octobre).

+ La trilogie des flous: "Je Ne», "Sommeil et rouge», "Reneiges», conception de Daniel Danis, Montréal, Usine C, 2008 (novembre).

+ Théâtre à lire avec Daniel Danis, Montréal, CEAD, 2009.

+ Les sens [de Michel Marc Bouchard, Sylvie Bouchard, Daniel Danis, Jean-Rock Gaudreault, Larry Tremblay, Pierre-Michel Tremblay], mise en scène de Benoît Lagrandeur, Jonquière, Théâtre de la Rubrique, 2011 (janvier).

+ La scaphandrière, mise en scène d'Olivier Letellier, Montréal, Théâtre Outremont, 2012 (novembre). 